\title{
JOURNAL.RU
}

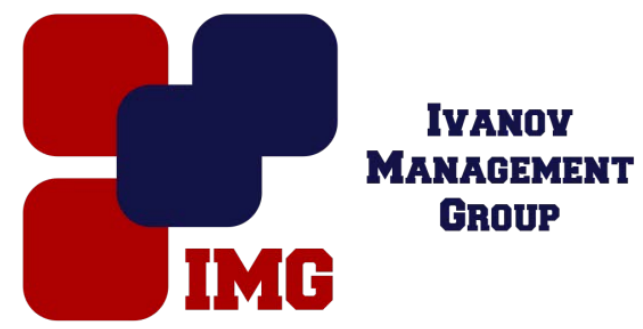

Калуцкая Н.А., Ансимова М.А. Белгородский государственный наииональный исследовательский университет Белгород, Россия

doi: 10.18411/lj-31-01-2017-2-05

idsp 000001:lj-31-01-2017-2-05

\section{Актуальные вопросы переоценки основных средств в современных условиях}

\section{Аннотация}

В статье изучена сущность переоценки основных средств, обосновывается необходимость ее проведения, анализируется ее влияние на величину налоговых платежей. Рассмотрены вопросы переоценки основных средств в соответствии с МСФО.

Ключевые слова: основные средства, последующая переоценка, ПБУ, МСФО.

Основные средства являются одним из важнейших элементов производственно-технической базы организаций, а грамотное построение их бухгалтерского учета является гарантией успешного функционирования любого хозяйствующего субъекта. В силу данных обстоятельств повышается значимость вопросов переоценки основных средств, так как на основе стоимостной оценки определяются показатели эффективности использования фондов и показатели финансового состояния организации. Помимо этого данные вопросы приобретают особую важность в ходе реформирования бухгалтерского учета в соответствии с МСФО, происходящего в настоящее время.

На сегодняшний момент учет основных средств регламентируется ПБУ 6/01 «Учет основных средств», согласно которому первоначальная стоимость объектов основных средств не подлежит изменению за исключением определенных законодательством случаев, одним из которых является переоценка [1].

В результате переоценки формируется восстановительная стоимость, которая есть ни что иное как стоимость воспроизводства основных средств в ценах, отражающих современные условия, или иными словами это сумма 
денежных средств, которая была бы потрачена предприятием на замену объекта в настоящий момент.

Решение об осуществлении переоценки с указанием ее периодичности должно быть закреплено в учетной политике предприятия, где помимо всего прочего необходимо указать группы основных средств, подлежащих переоценке; способ отражения переоценки в учете; перечень лиц, которые ответственны за проведение переоценки.

Целесообразность проведения переоценки основных средств может быть обусловлена следующими причинами: определение реальной стоимости объекта в соответствии с рыночными ценами; повышение уровня инвестиционной привлекательности; увеличение размера уставного капитала за счет добавочного; получение представления о реальном финансовом состоянии организации; повышение величины чистых активов; уточнение себестоимости продукции и формирование ее конкурентной цены; определение стоимости страховой базы имущества при заключении договора страхования; подготовка предприятия к купле-продаже.

Помимо того, что переоценка дает возможность приблизить стоимость основного средства по учетным данным к рыночной стоимости, она оказывает влияние на размер амортизационного фонда, балансовую оценку объекта, размер добавочного капитала и валюту баланса.

Иными словами переоценка выступает действенным механизмом управления показателями финансового состояния предприятия и делает показатели бухгалтерской отчетности более достоверными.

В то же время проведение переоценки может повлечь за собой негативные последствия. Увеличение первоначальной стоимости основного средства приводит к возрастанию размера налоговых платежей в бюджет, в частности в рамках налога на имущество. К тому же при отражении итогов переоценки возникают различия в бухгалтерском и налоговом учете, методика учета которых представляет собой достаточно сложный и трудоемкий процесс. Данная ситуация приводит к возникновению несоответствия между суммой амортизации, которая начисляется в бухгалтерском учете и суммой амортизации в налоговом. Различие между этими суммами формирует постоянную разницу, которая в свою очередь приводит к возникновению постоянного налогового актива или обязательства.

Сумма залогового обеспечения также может измениться, и в случае ее уменьшения, банком может быть предложено увеличение суммы залога.

Вышеописанные моменты необходимо принимать во внимание при намерении провести переоценку.

Следует отметить, что переоценка является правом организации, а не ее обязанностью. В то же время если предприятие решило переоценивать установленные группы основных средств, то в дальнейшем их переоценка будет регулярной, но не чаще чем раз в год. Такое условие требуется для того, чтобы стоимость объектов основных средств, по которой они отражаются в 
бухгалтерском учете, значительно не отличалась от текущей (восстановительной) стоимости.

Перед осуществлением переоценки организация проводит подготовительную работу, в частности, например, проверяет наличие самих объектов, которые подлежат переоценке.

Для того чтобы документально подтвердить измененную стоимость, предприятие составляет специальную ведомость результатов переоценки. Унифицированная форма данного документа отсутствует, в связи с чем организация вправе разработать ее самостоятельно и утвердить в качестве одного из приложений к учетной политике. Помимо этого, итоги переоценки основного средства должны быть отражены в разделе «Переоценка» инвентарной карточки данного объекта.

Результатом осуществленной переоценки является уценка или дооценка стоимости объекта, порядок отражения в бухгалтерском учете которого зависит оттого, переоценивался ли объект раньше или нет.

Сумма дооценки учитывается в качестве добавочного капитала предприятия. Сумма дооценки объекта, ранее переоценивавшегося в сторону уменьшения с отнесением суммы уценки на прочие расходы, подлежит отражению в качестве прочих доходов. Сумма уценки относится на финансовый результат в качестве прочих расходов. Сумма уценки объекта уменьшает добавочный капитал, который был ранее образован при предыдущих переоценках [2, с. 153].

Методическими указаниями по бухгалтерскому учету основных средств установлено два возможных способа проведения переоценки: индексация или прямой пересчет.

При первом методе восстановительная стоимость определяется с помощью индексов-дефляторов, разработанных Росстатом и дифференцированных по типам основных средств. Однако на текущий момент такие индексы официально Росстатом не публикуются, в связи с чем данный способ переоценки по сути не используется.

При втором методе восстановительная стоимость определяется пересчетом по документально подтвержденным рыночным ценам. Данный способ является наиболее точным и дает возможность исправить погрешности, которые были допущены в ходе предыдущих переоценок.

Поскольку индексный способ фактически не отменен, предприятию необходимо закрепить в своей учетной политике избранный метод переоценки и алгоритм пересчета.

Международные стандарты финансовой отчетности в отношении последующей оценки основных средств включают в себя следующие положения.

Согласно МСФО (IAS) 16 основные средства могут переоцениваться до справедливой стоимости при условии, что она поддается надежной оценке. 
Если имеет место переоценка некого объекта основных средств, то в данном случае переоценке на ту же дату подлежат также все основные средства того же класса, и такая переоценка должна проводиться регулярно. Под классом активов подразумевается группировка объектов по имеющимся у них сходным признакам, включающим их основные свойства и направление использования в деятельности предприятия.

Сумма дооценки актива, образующаяся в результате его переоценки, отражается в качестве прочего совокупного дохода и собственного капитала по статье «прирост стоимости от переоценки», за исключением случая, когда такое превышение перекрывает сумму прошлой уценки стоимости того же актива. В этом случае сумма дооценки актива в пределах отнесенной на расходы суммы признается в составе прибыли или убытка за период.

Снижение стоимости актива, образующееся в результате его переоценки, признается в качестве прибыли или убытка за период, за исключением случая, когда такое снижение перекрывает ранее признанную сумму дооценки по тому же самому активу. В этом случае соответствующая сумма отражается в составе прочего совокупного дохода и уменьшает сумму, которая была ранее накоплена в составе собственного капитала по статье «прирост стоимости от переоценки».

Сумма дооценки актива, признанная при его переоценке, может быть перенаправлена на счет нераспределенной прибыли в момент прекращения признания данного объекта. В соответствии с МСФО (IAS) 16 считается, что реализация дооценки имеет место либо при эксплуатации актива, либо при его последующем выбытии или прекращении эксплуатации [3, с. 370].

Результаты переоценки отражаются в бухгалтерской отчетности на конец отчетного периода следующим образом.

В бухгалтерском балансе в разделе III «Капитал и резервы» по строке «Переоценка внеоборотных активов» отражается дооценка объектов основных средств.

В отчете о финансовых результатах итоги переоценки, которые подлежат к зачислению в прочие доходы или расходы, отражаются по строке «Прочие доходы» и строке «Прочие расходы» соответственно. Суммы изменения добавочного капитала по итогам переоценки отражаются справочно по строке «Результат от переоценки внеоборотных активов, не включаемый в чистую прибыль (убыток) периода».

В отчете об изменениях капитала для отражения результатов переоценки используются специальные строки «Переоценка имущества» в рамках расшифровки показателей «Увеличение капитала - всего» и «Уменьшение капитала - всего».

Подводя итог, можно сказать, что со временем первоначальная стоимость основных средств отклоняется от стоимости аналогичных объектов, которые были приобретены или введены в эксплуатацию в настоящем периоде. С целью устранения данного расхождения возникает необходимость в периодической переоценке основных средств и определении их восстановительной стоимости. 
Таким образом, переоценка основных средств хозяйствующим субъектам необходима для их эффективного развития, повышения качества и конкурентоспособности выпускаемой продукции.

На сегодняшний момент учет основных средств регламентируется ПБУ 6/01 «Учет основных средств», согласно которому первоначальная стоимость объектов основных средств не подлежит изменению за исключением определенных законодательством случаев, одним из которых является переоценка [1].

В результате переоценки формируется восстановительная стоимость, которая есть ни что иное как стоимость воспроизводства основных средств в ценах, отражающих современные условия, или иными словами это сумма денежных средств, которая была бы потрачена предприятием на замену объекта в настоящий момент.

Решение об осуществлении переоценки с указанием ее периодичности должно быть закреплено в учетной политике предприятия, где помимо всего прочего необходимо указать группы основных средств, подлежащих переоценке; способ отражения переоценки в учете; перечень лиц, которые ответственны за проведение переоценки.

Целесообразность проведения переоценки основных средств может быть обусловлена следующими причинами: определение реальной стоимости объекта в соответствии с рыночными ценами; повышение уровня инвестиционной привлекательности; увеличение размера уставного капитала за счет добавочного; получение представления о реальном финансовом состоянии организации; повышение величины чистых активов; уточнение себестоимости продукции и формирование ее конкурентной цены; определение стоимости страховой базы имущества при заключении договора страхования; подготовка предприятия к купле-продаже.

Помимо того, что переоценка дает возможность приблизить стоимость основного средства по учетным данным к рыночной стоимости, она оказывает влияние на размер амортизационного фонда, балансовую оценку объекта, размер добавочного капитала и валюту баланса.

Иными словами переоценка выступает действенным механизмом управления показателями финансового состояния предприятия и делает показатели бухгалтерской отчетности более достоверными.

В то же время проведение переоценки может повлечь за собой негативные последствия. Увеличение первоначальной стоимости основного средства приводит к возрастанию размера налоговых платежей в бюджет, в частности в рамках налога на имущество. К тому же при отражении итогов переоценки возникают различия в бухгалтерском и налоговом учете, методика учета которых представляет собой достаточно сложный и трудоемкий процесс. Данная ситуация приводит к возникновению несоответствия между суммой амортизации, которая начисляется в бухгалтерском учете и суммой амортизации в налоговом. Различие между этими суммами формирует постоянную разницу, 
которая в свою очередь приводит к возникновению постоянного налогового актива или обязательства.

Сумма залогового обеспечения также может измениться, и в случае ее уменьшения, банком может быть предложено увеличение суммы залога.

Вышеописанные моменты необходимо принимать во внимание при намерении провести переоценку.

Следует отметить, что переоценка является правом организации, а не ее обязанностью. В то же время если предприятие решило переоценивать установленные группы основных средств, то в дальнейшем их переоценка будет регулярной, но не чаще чем раз в год. Такое условие требуется для того, чтобы стоимость объектов основных средств, по которой они отражаются в бухгалтерском учете, значительно не отличалась от текущей (восстановительной) стоимости.

Перед осуществлением переоценки организация проводит подготовительную работу, в частности, например, проверяет наличие самих объектов, которые подлежат переоценке.

Для того чтобы документально подтвердить измененную стоимость, предприятие составляет специальную ведомость результатов переоценки. Унифицированная форма данного документа отсутствует, в связи с чем организация вправе разработать ее самостоятельно и утвердить в качестве одного из приложений к учетной политике. Помимо этого, итоги переоценки основного средства должны быть отражены в разделе «Переоценка» инвентарной карточки данного объекта.

Результатом осуществленной

переоценки

является уценка или дооценка стоимости объекта, порядок отражения в бухгалтерском учете которого зависит оттого, переоценивался ли объект раньше или нет.

Сумма дооценки учитывается в качестве добавочного капитала предприятия. Сумма дооценки объекта, ранее переоценивавшегося в сторону уменьшения с отнесением суммы уценки на прочие расходы, подлежит отражению в качестве прочих доходов. Сумма уценки относится на финансовый результат в качестве прочих расходов. Сумма уценки объекта уменьшает добавочный капитал, который был ранее образован при предыдущих переоценках [2, с. 153].

Методическими указаниями по бухгалтерскому учету основных средств установлено два возможных способа проведения переоценки: индексация или прямой пересчет.

При первом методе восстановительная стоимость определяется с помощью индексов-дефляторов, разработанных Росстатом и дифференцированных по типам основных средств. Однако на текущий момент такие индексы официально Росстатом не публикуются, в связи с чем данный способ переоценки по сути не используется.

При втором методе восстановительная стоимость определяется пересчетом по документально подтвержденным рыночным ценам. Данный способ является 
наиболее точным и дает возможность исправить погрешности, которые были допущены в ходе предыдущих переоценок.

Поскольку индексный способ фактически не отменен, предприятию необходимо закрепить в своей учетной политике избранный метод переоценки и алгоритм пересчета.

Международные стандарты финансовой отчетности в отношении последующей оценки основных средств включают в себя следующие положения.

Согласно МСФО (IAS) 16 основные средства могут переоцениваться до справедливой стоимости при условии, что она поддается надежной оценке.

Если имеет место переоценка некого объекта основных средств, то в данном случае переоценке на ту же дату подлежат также все основные средства того же класса, и такая переоценка должна проводиться регулярно. Под классом активов подразумевается группировка объектов по имеющимся у них сходным признакам, включающим их основные свойства и направление использования в деятельности предприятия.

Сумма дооценки актива, образующаяся в результате его переоценки, отражается в качестве прочего совокупного дохода и собственного капитала по статье «прирост стоимости от переоценки», за исключением случая, когда такое превышение перекрывает сумму прошлой уценки стоимости того же актива. В этом случае сумма дооценки актива в пределах отнесенной на расходы суммы признается в составе прибыли или убытка за период.

Снижение стоимости актива, образующееся в результате его переоценки, признается в качестве прибыли или убытка за период, за исключением случая, когда такое снижение перекрывает ранее признанную сумму дооценки по тому же самому активу. В этом случае соответствующая сумма отражается в составе прочего совокупного дохода и уменьшает сумму, которая была ранее накоплена в составе собственного капитала по статье «прирост стоимости от переоценки».

Сумма дооценки актива, признанная при его переоценке, может быть перенаправлена на счет нераспределенной прибыли в момент прекращения признания данного объекта. В соответствии с MCФО (IAS) 16 считается, что реализация дооценки имеет место либо при эксплуатации актива, либо при его последующем выбытии или прекращении эксплуатации [3, с. 370].

Результаты переоценки отражаются в бухгалтерской отчетности на конец отчетного периода следующим образом.

В бухгалтерском балансе в разделе III «Капитал и резервы» по строке «Переоценка внеоборотных активов» отражается дооценка объектов основных средств.

В отчете о финансовых результатах итоги переоценки, которые подлежат к зачислению в прочие доходы или расходы, отражаются по строке «Прочие доходы» и строке «Прочие расходы» соответственно. Суммы изменения добавочного капитала по итогам переоценки отражаются справочно по строке 
«Результат от переоценки внеоборотных активов, не включаемый в чистую прибыль (убыток) периода».

В отчете об изменениях капитала для отражения результатов переоценки используются специальные строки «Переоценка имущества» в рамках расшифровки показателей «Увеличение капитала - всего» и «Уменьшение капитала - всего».

Подводя итог, можно сказать, что со временем первоначальная стоимость основных средств отклоняется от стоимости аналогичных объектов, которые были приобретены или введены в эксплуатацию в настоящем периоде. С целью устранения данного расхождения возникает необходимость в периодической переоценке основных средств и определении их восстановительной стоимости.

Таким образом, переоценка основных средств хозяйствующим субъектам необходима для их эффективного развития, повышения качества и конкурентоспособности выпускаемой продукции.

\section{Литература}

1. Об утверждении Положения по бухгалтерскому учету «Учет основных средств» ПБУ 6/01» [Электронный ресурс] : Приказ Минфина РФ от 30.03.2001 № 26н // Справочная правовая система «Консультант Плюс».

2. Кондраков, Н.П. Бухгалтерский финансовый учет [Текст] : учеб. пособие / Н.П. Кондраков - М.: Инфра-М, 2012. - 832 с.

3. Леонова, С.В. Сравнительная характеристика МСФО 16 «Основные средства» и ПБУ 6/01 «Учет основных средств» [Текст] / С.В. Леонова // Вестник Тульского филиала финансового университета - 2014 - № 1. - С. 369-371. 